Session 2230

\title{
Effects of Reciprocal Peer Tutoring on Student Performance in an Environmental Control Systems Course at an Undergraduate Level
}

\author{
Ifte Choudhury \\ Texas A\&M University \\ College Station
}

\begin{abstract}
The purpose of this study was to examine the effects of reciprocal peer tutoring (RPT) on student performance in one of the Environmental Control Systems courses offered by the Department of Construction Science, Texas A\&M University. Reciprocal peer tutoring has been used extensively at school level for developing academic skills of the students. It has also been used at college level for different disciplines. In this technique, students occasionally function equally as both tutor and tutee in a classroom situation. It enables the students to gain both from the preparation and instruction in which the tutors engage, and from the instructions that the tutees receive. Apart from RPT, some other probable correlates of student performance such as gender difference, overall academic ability of a student, semester in which the course was offered (summer vs. regular), and the academic major of a student were also taken into consideration to determine whether RPT continues to remain statistically significant in the presence of these variables. The study population consisted of the students who attended the course in Summer terms of 1998 and 2000, and Spring semester of 2000. Sample size of the study was 156 students. Relevant data was collected from the Student Information Management System database of the university. The data was analyzed using stepwise regression procedure and a General Linear Model. The findings generated from the analysis of the data indicated that RPT has a statistically significant effect on student performance in this particular Environmental Control Systems course. Overall academic ability and the academic major of a student are also positively correlated with student performance.
\end{abstract}

Key words: General Linear Model, Environmental Control Systems, Reciprocal Peer Tutoring, Stepwise Regression, Undergraduate Education.

I. Statement of the Problem

Peer tutoring is a cooperative learning strategy that capitalizes on the benefits students receive from preparing to tutor one another. It has been found to be an effective technique for increasing students' academic achievement ${ }^{1,2,3}$. Literature indicates that both the tutors and tutees attain a better understanding of the materials by participating in the process ${ }^{4,5}$.

Advancing this strategy a step further, a few other researchers have developed a procedure that enables all the members in a group to participate in the role of the tutor. This is known as reciprocal peer tutoring (RPT). In this technique, students function equally as both tutor and 
tutee. It enables the students to gain both from the preparation and instruction in which the tutors engage, and from the instructions that the tutees receive ${ }^{6}$.

Reciprocal peer tutoring has been used extensively at school for developing academic skills of the students. It has also been used at college level for different disciplines. Some studies indicate that this teaching procedure help the students improve their academic skills ${ }^{7,8}$. There are yet other findings that do not provide a strong support for the effectiveness of the procedure ${ }^{9}$.

The Department of Construction Science within the College of Architecture at Texas A\&M University offers Environmental Control Systems courses at an undergraduate level. Apart from Construction Science students, Environmental Design students of the College of Architecture also take these courses. The author introduced reciprocal peer tutoring (RPT) to teach an Environmental Control Systems course in the summer of 2000. It appeared that the student performance in that class was significantly higher than the previous classes in which RPT was not adopted. The purpose of this study is to test the hypothesis that reciprocal peer tutoring has an effect on student performance in Environmental Control Systems courses.

Apart from RPT, some other probable correlates of student performance such as gender difference, overall academic ability of a student, semester in which the course was offered (summer vs. regular), and the academic major of a student were also taken into consideration to determine whether RPT continues to remain statistically significant in the presence of these variables. Student performance in an Environmental Control Systems course was, in fact, found also to be affected by the overall academic ability and gender difference of the students ${ }^{10}$.

\section{Methodology}

\section{Study Population}

The study population consists of the students who registered for and actually attended Environmental Control Systems I course offered by the Department of Construction Science, Texas A\& M University, in the following semesters:

1. Summer I, 1998

2. Spring, 2000

3. Summer I, 2000.

The sample size was 156 . The entities under study are the students who attended these classes. The unit of analysis is the student.

\section{Data Collection Procedure}

Reciprocal peer tutoring technique was adopted for teaching the class of Summer I, 2000. The class was divided into small groups ranging from three to five students. The groups met every alternate day during the class period, discussed the materials that were presented by the tutor on the previous day, developed a series of questions on the materials, and used the questions to quiz each other. The questions with correct answers were handed over to the tutor at the end of the 
class. Students in this class formed the treatment group. Students from rest of the semesters formed the control group.

The final grades of the students in the course were recorded as student performance. Data related to academic major, gender difference, and overall academic ability of the students was collected from the Student Information Management System of Texas A\&M University.

Variables and their Operationalization

Student Performance (GRADE). Student performance is the actual academic performance of the student in the class. It was measured by the percentage of total numerical grade obtained by the student in the course.

Semester (SEMESTER): Semester is an academic term during which the student attended the course. It was categorized into two groups: 1) regular semesters consisting of fall and spring semesters and 2) summer semesters or terms. The regular semesters have duration of 15 weeks each, while the summer terms have a shorter duration of 5 weeks each. This variable was included to measure the effect of semesters on student performance. It is a dummy variable, which took on a value of 1 for a regular semester and 0 for a summer semester.

Sex (SEX): Sex is the gender identification of a student. It is a dummy variable, which took on a value of 1 for females and 0 for males.

Grade Point Average (GPA): It is the reported overall grade point average of the student. It ranges from 0 to 4 . It was used as a proxy for overall academic ability of a student.

Reciprocal Peer Tutoring (RPT): This variable was included to measure the effect of the particular teaching method on student performance. It is a dummy variable, which took on a value of 1 for a class in which RPT was adopted and 0 for a class in which it was not adopted.

III. Analysis and Interpretation

Results

A stepwise regression analysis was first performed using a forward-selection procedure setting the significance level of entry at 0.2 . This was done in order to determine the relative importance of the variables with respect to their contribution in explaining the variance of student performance $(G R A D E)$. The following model was used for the analysis:

$G R A D E=\mathrm{b}_{0}+\mathrm{b}_{1} G P A+\mathrm{b}_{2} S E M E S T E R+\mathrm{b}_{3} S E X+\mathrm{b}_{4} M A J O R+\mathrm{b}_{5} R P T+\mathrm{e}$

where $b_{0}=$ intercept,

$b_{1}, b_{2}$, etc $=$ regression coefficients, and

$\mathrm{e}=$ error term. 
Results of the analysis indicated that only GPA, MAJOR, and RPT (entered in the model in that order) were correlated with GRADE at the level of significance of 0.2 (Table 1). Both SEMESTER and SEX were not statistically significant at that level.

Further analysis was performed using a General Linear Model with RPT as a classification variable. This was done primarily to verify the results obtained by the stepwise regression analysis. The results are shown in Table 2.

Table 1

Summary of Stepwise Procedure for GRADE

\begin{tabular}{llllll}
\hline $\begin{array}{l}\text { Variable } \\
\text { Entered }\end{array}$ & Step & Partial $R^{2}$ & Model $R^{2}$ & $F$-value & $p>F$ \\
\hline \hline GPA & 1 & 0.4065 & 0.4065 & 105.4874 & 0.0001 \\
MAJOR & 2 & 0.0813 & 0.4878 & 24.2724 & 0.0001 \\
RPT & 3 & 0.0253 & 0.5131 & 2.7239 & 0.0056 \\
\hline \hline
\end{tabular}

Table 2

General Linear Model Analysis for GRADE

\begin{tabular}{llllll}
\hline Variable & Intercept & $\begin{array}{l}\text { Coefficient of the } \\
\text { independent variables }\end{array}$ & $T$ & $p>|T|$ & $\begin{array}{l}\text { Critical Value } \\
\text { of }|T|\end{array}$ \\
\hline \hline Intercept & 50.87 & & 15.35 & 0.0001 & 1.29 \\
GPA & 11.08 & 10.96 & 0.0001 & \\
MAJOR & 4.44 & 5.13 & 0.0001 & \\
RPT & 2.79 & 2.81 & 0.0056 & \\
\hline \hline
\end{tabular}

$F$-value of the $\quad p>$ Model $\quad$ Model $R^{2}=0.51$

Model $=53.38 \quad F=0.0001$

The least-squares means of $G R A D E$ for each effect of the classification variable $R P T$ were computed using LSMEANS statement. Table 3 shows the results.

Table 3

Least-Squares Means of GRADE for the effects of RPT

\begin{tabular}{llll}
\hline$R P T$ & GRADE LSMEANS & $T$ & $p>|T|$ \\
\hline 0 & 82.15 & 2.81 & 0.0056 \\
1 & 84.94 & & \\
\hline \hline
\end{tabular}

Proceedings of the 2001 American Society for Engineering Education Annual Conference \& Exposition Copyright (C) 2001, American Society for Engineering Education 


\section{Interpretations}

General Linear Method was used multiple regression analysis. The $F$-value of the model was found to be statistically significant at the 0.0001 level. However, the predictive efficacy of the model was found to be moderately high with an $R^{2}$ of 0.51 . Such values are considered to be satisfactory related to empirical studies in social sciences ${ }^{11}$.

The results of the stepwise regression procedure, confirmed by those obtained by General Linear Method, indicated that student performance in the Environmental Control Systems course used for the study was affected by both overall academic ability and academic major of a student at the 0.0001 level of significance. Reciprocal peer tutoring was also found to have a positive relationship with student performance in the presence of these variables at a level of significance of 0.01 ( 0.0056 to be exact). The results of the stepwise regression procedure indicated that neither gender difference nor semester was correlated to student performance in an Environmental Control Systems course.

\section{Discussion}

Reciprocal peer tutoring $(R P T)$ was found to have a significant effect on student performance at the 0.01 level. This is probably because of the reason that cooperative learning results in higher level of reasoning and more frequent generation of ideas and solutions than individualistic learning. Literature indicates that students tend to form multidimensional and realistic impressions of one another's competencies and give accurate feedback in a reciprocal peer tutoring process ${ }^{12}$.

Academic major of a student (MAJOR) was found to be a statistically significant predictor of student performance at the 0.0001 level. The course has been designed to meet the requirements for an undergraduate degree in Construction Science. Because of this reason it is possible that non-majors who take this course may lack an understanding of some of the concepts in order to appreciate the course and, therefore, are intimidated by the course content.

The most statistically significant predictor of student performance was found to be the academic ability of student, measured by the student's overall grade point average (GPA). Studies on education indicate overall grade point average is positively correlated with overall grade point average. Findings by Seymour et al. ${ }^{13}$ reveal that most significant factor in predicting success in a business microcomputer course is the overall grade point average of a student. Similar findings have been reported by Rose et al. ${ }^{14}$ in a study of student performance in an introductory psychology course. It was, therefore, likely to find a positive relationship between student performance in an Environmental Control System course and overall grade point average.

An informal discussion with the students using RPT revealed that their perceptions about the technique were positive. Nearly all of them agreed that the technique was useful because it forced them to apply the course content and provided additional review and practice. It made them better prepared for the tests and to complete the major class assignments. However, the results should be viewed with caution because the technique had been adopted for only one class 
in a summer semester. For future studies, it will be worthwhile to use data from regular semesters with RPT effect.

Bibliography

1. Jenkins, J. \& Jenkins, L. Peer tutoring in elementary and secondary programs. Focus on Exceptional Children, 17, 3-12 (1985).

2. Magolda, M. B. \& Rogers, J. L. Peer tutoring: Collaborative to enhance intellectual development. The College Student Journal, 21, 288-296 (1987).

3. Slavin, R. E. Synthesis of research on cooperative learning. Educational Leadership, 48, 71-82 (1991).

4. Annis, L. F. The processes and effects of peer tutoring. Human Learning, 2, $39-47$ (1983).

5. Sherman, L W. Cooperative learning in post secondary education: Implications from social psychology for active learning experiences. Paper presented at the annual meeting of the American Educational Research Association (1991).

6. Griffin, B. W. \& Griffin, M. M. The effects of reciprocal peer tutoring on graduate students' achievement, test anxiety, and academic self-efficacy. The Journal of Experimental Education, 65, 197-209 (1997).

7. Gartner, A. J. \& Riessman, F. Tutoring helps those who give, those who receive. Educational Leadership, 52, 5860 (1994).

8. Kohler, F. W. \& Greenwood, C. R. Effects of collateral peer supportive behaviors within the classwide peer tutoring program. Journal of Applied Behavior Analysis, 23, 307-322 (1990).

9. Griffin, B. W. \& Griffin, M. M. An investigation of the effects of peer tutoring on achievement, self-efficacy, and test anxiety. Contemporary Educational Psychology, 23, 298-311 (1998).

10. Choudhury, I. Correlates of Student Performance in Environmental Control Systems Courses at an

Undergraduate Level. San Luis Obispo, CA: Proceedings of the $35^{\text {th }}$ Annual Conference of the Associated Schools of Construction, 21-28 (1999).

11. Freund, R. J. \& Wilson, W. J. Statistical methods. College Station, Texas: Texas A\&M University (1991).

12. Johnson, R. T. \& Johnson, D. W. An overview of cooperative learning. In Thousand, J. S., Villa, R. A. \& Nevin, A. I. (Eds.), Creativity and collaborative learning: A practical guide to students and teachers (pp. 31-44).

Baltimore, MD: Paul H. Brookes Publishing Co. (1994).

13. Seymour, J., Goings, D., \& Vincent, A. Factors contributing to success in a microcomputer course. Perceptual and Motor Skills, 79, 1338 (1994).

14. Rose, R. J., Hall, C. W., \& Bolen, L. M. Locus control and college students' approaches to learning.

Psychological Reports, 79, 163-171 (1996).

\section{IFTE CHOUDHURY}

Ifte Choudhury is an Assistant Professor in the Department of Construction Science. He received a B. Arch. from Bangladesh University of Engineering \& Technology, an M. Phil. in Architecture from the University of Newcastleupon-Tyne in England, and a Ph. D. in Architecture from Texas A\&M University. Dr. Choudhury has extensive experience as a consulting architect working on projects funded by the World Bank, Asian Development Bank, and some other Multilateral Development Banks. His areas of emphasis include housing, alternative technology, issues related to international construction, and construction education. He teaches Environmental Control Systems at an undergraduate level and International Construction at a graduate level.

Proceedings of the 2001 American Society for Engineering Education Annual Conference \& Exposition Copyright $\odot$ 2001, American Society for Engineering Education 